\title{
Enhanced Locomotor, Reinforcing, and Neurochemical Effects of Cocaine in Serotonin 5-Hydroxytryptamine 2C Receptor Mutant Mice
}

\author{
Beatriz A. Rocha, ${ }^{1,2 *}$ Evan H. Goulding, ${ }^{3 *}$ Laura E. O'Dell, ${ }^{4}$ Andy N. Mead, ${ }^{1}$ Nicole G. Coufal, ${ }^{3}$ \\ Loren H. Parsons, ${ }^{4}$ and Laurence H. Tecott ${ }^{3}$ \\ ${ }^{1}$ National Institute on Drug Abuse/Intramural Research Program, Baltimore, Maryland 21224, 2 University of Maryland/ \\ Maryland Psychiatric Research Center, Baltimore, Maryland 21247, ${ }^{3}$ Department of Psychiatry and Center for \\ Neurobiology and Psychiatry, University of California, San Francisco, San Francisco, California 94143-0984, and \\ ${ }^{4}$ Department of Neuropharmacology, The Scripps Research Institute, La Jolla, California 92037
}

\begin{abstract}
Brain serotonin [5-hydroxytryptamine (5-HT)] systems substantially influence the effects of cocaine; however, the contributions of individual 5-HT receptor subtypes to the regulation of cocaine responses are unclear. A line of mutant mice devoid of 5-HT2C receptors was used to examine the contribution of this receptor subtype to the serotonergic modulation of cocaine responses. Mutants display enhanced exploration of a novel environment and increased sensitivity to the locomotor stimulant effects of cocaine. In an operant intravenous self-administration model under a progressive ratio schedule of reinforcement, mutants display elevated levels of lever pressing for cocaine injections, indicating that the
\end{abstract}

Cocaine dependence is a major worldwide public health problem (Strang et al., 1993; Withers et al., 1995) with an estimated 1.2 million users in the United States alone (Epstein, 2000). Effective pharmacological treatments for cocaine abuse are not yet available (Kranzler et al., 1999), highlighting the need for new insights into the neural mechanisms that underlie the actions of cocaine. Cocaine binds with high affinity to the dopamine (DA), norepinephrine, and 5-HT transporters (Koe, 1976; Reith et al., 1997), thereby blocking reuptake of these monoamines and increasing their extracellular concentrations in the brain. Activation of the mesolimbic DA system, consisting of projections from the midbrain ventral tegmental area (VTA) to forebrain regions, including the nucleus accumbens (NAcc), is considered a critical event underlying the psychostimulant and reinforcing effects of cocaine (Wise, 1984). In general, activation of the serotonergic system appears to inhibit these effects of cocaine, whereas manipulations that decrease serotonergic transmission increase the psychostimulant and reinforcing properties of cocaine (Carroll et al., 1990; Loh and Roberts, 1990; Morrow and Roth, 1996; Herges and Taylor, 1999). Serotonergic neurons in the dorsal raphe project to

Received June 5, 2002; revised Sept. 3, 2002; accepted Sept. 10, 2002.

This work was supported by the NIDA Ernest Gallo Clinic and Research Center, by National Institute on Drug Abuse (NIDA) Grant DA 11177 (L.H.T.), by an R29 NIDA Grant DA 12579 (B.A.R.), and by a Howard Hughes Medical Institute Physician Postdoctoral Fellowship (E.H.G.). We thank Noura Sall, Jean Danao, Robert Ator, and Isis Green for technical assistance.

*B.A.R. and E.H.G. contributed equally to this work.

Correspondence should be addressed to Laurence H. Tecott, 401 Parnassus Avenue, IRE-0984, San Francisco, CA 94143. E-mail: tecott@itsa.ucsf.edu.

B. Rocha's present address: Department of Pharmacology, Merck Research Laboratories, Rahway, NJ 07065.

A. N. Mead's present address: Laboratory of Experimental Psychology, School of Biological Sciences, University of Sussex, Brighton, BN19QG, UK.

Copyright (C) 2002 Society for Neuroscience $0270-6474 / 02 / 2210039-07 \$ 15.00 / 0$ drug is more reinforcing in these mice. Moreover, mutants exhibit enhanced cocaine-induced elevations of dopamine (DA) levels in the nucleus accumbens, a brain region implicated in the stimulant and rewarding properties of cocaine. In contrast, phenotypic differences in dorsal striatal DA levels were not produced by cocaine treatment. These findings strongly implicate $5-\mathrm{HT} 2 \mathrm{C}$ receptors in the serotonergic suppression of DA-mediated behavioral responses to cocaine and as a potential therapeutic target for cocaine abuse.

Key words: cocaine; serotonin; serotonin $2 c$ receptor; behavior; reinforcement; mice

the VTA and the NAcc (Azmitia and Segal, 1978; Herve et al., 1987; Van Bockstaele et al., 1994; Van Bockstaele et al., 1996) and influence dopaminergic transmission (Herve et al., 1979; Kelland et al., 1993; Prisco and Esposito, 1995; Brodie and Bunney, 1996), suggesting that regulation of mesolimbic dopaminergic activity may play an important role in the serotonergic modulation of cocaine effects. Elucidation of the 5-HT receptor subtype(s) mediating these effects may therefore identify novel targets for the development of pharmacological agents useful in the treatment of cocaine abuse.

Recent evidence suggests that activation of 5-HT2C receptors may contribute substantially to a serotonergic inhibition of mesolimbic dopaminergic activity. Notably, 5-HT2C receptors are expressed in the VTA, where their activation decreases the firing of dopaminergic neurons and reduces DA levels in the NAcc (Di Giovanni et al., 2000; Gobert et al., 2000). However, the effects of pharmacological manipulations of 5-HT2C receptors on behavioral responses to cocaine have been inconsistent (Lacosta and Roberts, 1993; Peltier et al., 1994; Callahan and Cunningham, 1995; McCreary and Cunningham, 1999; Grottick et al., 2000; McMahon et al., 2001), most likely because of the limited specificity of available pharmacological agents. Therefore, the hypothesis that 5-HT2C receptors substantially contribute to serotonergic inhibition of mesolimbic DA transmission and behavioral responses to cocaine was tested using mice lacking this receptor subtype (5-HT2C receptor null mutant mice) (Tecott et al., 1995).

\section{MATERIALS AND METHODS}

Animals. 5-HT2C receptor null mutant mice were generated from a 129-derived embryonic stem cell line and bred and genotyped as described previously (Tecott et al., 1995). Male wild-type (WT) and null hemizygous mutant mice resulting from $\geq 16$ generations of backcrossing 
to the $\mathrm{C} 57 \mathrm{BL} / 6 \mathrm{~J}$ background were used in these experiments. Animals were housed at $22^{\circ} \mathrm{C}$ on a $12 \mathrm{hr}$ light/dark cycle (lights off at 7:00 P.M.) with ad libitum access to water and a standard chow diet (PicoLab Mouse Diet 20; Purina Mills, Richmond, IN). No phenotypic differences in body weight were observed for the cohorts of animals used in this study. Investigators were blind to the genotypes of the mice during all behavioral studies and to the cocaine doses administered during locomotor and dialysis studies. Experiments were performed in accordance with guidelines of the National Institutes of Health Guide for Care and Use of Laboratory Animals, the University of California San Francisco Committee on Animal Research, the Scripps Research Institute Animal Care and Use Committee, and the National Institute on Drug Abuse/Intramural Research Program Animal Care and Use Committee.

Locomotor activity. Horizontal activity was assessed as described previously (Heisler and Tecott, 2000). Mice were placed in the monitoring apparatus and injected $2 \mathrm{hr}$ later with saline $(10 \mathrm{ml} / \mathrm{kg}$, i.p.), on days $1-3$, and $0,7.5,15$, or $30 \mathrm{mg} / \mathrm{kg}$ cocaine (cocaine hydrochloride; Sigma, St. Louis, MO) freshly dissolved in saline, on day 4. After injection, mice were returned to the apparatus for 2 additional hours. Before the day of cocaine injection, locomotor responses to saline injection appeared stable and without phenotypic difference as demonstrated by a $2 \times 2$ ANOVA with one repeated measure, which showed no statistically significant effect of genotype or day and no interaction for locomotion during the hour after injection on habituation days 2 and 3. Mice were tested weekly in groups of eight (four WT and four mutants per week; WT, $n=63$; mutant, $n=62$ ), with 15-16 mice per genotype per dose.

Cocaine and metabolite assay. Animals were rapidly decapitated $(n=6$ per genotype) $30 \mathrm{~min}$ after intraperitoneal injections of $30 \mathrm{mg} / \mathrm{kg}$ cocaine. Cocaine, norcocaine, and benzoylecgonine were extracted from mouse brain tissue according to the method of Benuck et al. (1987). Tropacocaine $(0.7755 \mu \mathrm{g}$ in $100 \mu \mathrm{l})$ was used as an internal standard and added to the tissue before extraction. All analyte values were normalized to the extraction efficiency of tropacocaine on a per sample basis. The average extraction efficiency for all samples was $16 \pm 1.5 \%$ (average of 56 extractions). Extracted samples were subsequently analyzed using a microbore HPLC system optimized for the separation of benzoylecgonine, tropacocaine, cocaine, and norcocaine within a 30 min elution time. Analytes were detected by a SpectraFocus scanning UV detector (SpectraPhysics, San Jose, CA) at a wavelength of $225 \mathrm{~nm}$. External calibration curves for each analyte were generated daily for fresh standard solutions in $0.25 \mathrm{~mm}$ ascorbic acid. The limit of quantitation was $<1$ pmol on a column for each analyte. No phenotypic differences were observed in cocaine [nanograms per milligram of tissue; WT, $9.3 \pm 1.7$; mutant, $10.8 \pm 2.9($ mean \pm SEM) $]$, norcocaine (WT, $1.6 \pm 0.2$; mutant, $1.4 \pm$ 0.1 ), or benzoylecgonine (WT, $1.2 \pm 0.2$; mutant, $1.1 \pm 0.2$ ) levels.

Microdialysis. Details of microdialysis probe construction, implantation, and experimental conditions have been described previously (Parsons et al., 1995). Approximately $12 \mathrm{hr}$ before the start of dialysis sampling, each mouse (WT, $n=10$; mutant, $n=9$ ) was anesthetized (1-2\% Halothane by inhalation) and stereotaxically implanted with two microdialysis probes. In a counterbalanced manner, one was placed into the left or right NAcc [anteroposterior (AP), -1.5 ; mediolateral (ML), \pm 0.8 ; dorsoventral (DV), $-5.3 \mathrm{DV}]$ and one into the contralateral dorsal striatum (DStr) (AP, +0.5; ML, $\pm 2 ; \mathrm{DV},-5)$. The active membrane length was $1 \mathrm{~mm}$ for NAcc probes and $2 \mathrm{~mm}$ for DStr probes. The perfusate flow rate to both probes was $0.2 \mu \mathrm{l} / \mathrm{min}$ for the first 10 postsurgical hours and then increased to $0.6 \mu \mathrm{l} / \mathrm{min} 1 \mathrm{hr}$ before the start of dialysate collection and for the remainder of the experiment. Baseline dialysate samples were collected at $10 \mathrm{~min}$ intervals for $50 \mathrm{~min}$. Subsequently, all mice received an injection of cocaine $(15 \mathrm{mg} / \mathrm{kg}$, i.p.) followed by an additional $120 \mathrm{~min}$ of dialysate sampling. After collection, dialysate samples were immediately frozen and stored at $-70^{\circ} \mathrm{C}$ until analysis for DA content by microbore HPLC (Parsons et al., 1995). External calibration curves for DA were constructed daily using fresh DA standards, and the on-column limit of quantitation $(\mathrm{S} / \mathrm{N}=3)$ was 0.5 fmol of DA corresponding to a concentration of $0.1 \mathrm{nM}$. All microdialysis experiments were conducted $\geq 4 \mathrm{hr}$ after the onset of the light cycle. Each animal in the final data set had correct probe placements in both regions as determined histologically.

Self-administration. Self-administration experiments took place in mouse operant chambers (model ENV-300; Med Associates, St. Albans, VT). Chambers were equipped with two levers, and the responses on one lever (active lever) delivered one reinforcer, whereas responses on the second lever had no programmed consequences (inactive lever). Mice were initially trained to respond for a $15 \%$ condensed milk solution under a fixed ratio 1 (FR1) schedule, in which each active lever press delivered one reinforcer. All mice met criteria for food shaping acquisition (3:1 ratio of active/inactive lever presses and $\geq 300$ reinforcers per session) within three training sessions. After food shaping, mice were anesthetized (18 $\mathrm{mg} / \mathrm{kg}$ xylazine and $80 \mathrm{mg} / \mathrm{kg}$ ketamine solution, i.p.) and implanted with an indwelling intravenous catheter in the right jugular, as described previously (Rocha et al., 1998a). Two days after surgery, mice started cocaine self-administration under a FR1 schedule $\left(1 \mathrm{mg} / \mathrm{kg}^{-1} / 0.02 \mathrm{ml}^{-1}\right)$; each daily session lasted until either 20 injections were obtained or $3 \mathrm{hr}$ had elapsed. After completion of criteria for cocaine self-administration (3:1 ratio of active/inactive lever presses and $\geq 15$ injections for 3 consecutive days), mice were switched to the progressive ratio (PR) schedule, under which the number of active lever presses required to obtain each subsequent injection was based on the adapted exponential sequence: $3,5,7,9,12,15,18,23,28,33,41,49,57$, $70,83,96,117$. . (Rocha et al., 1998a). PR sessions lasted for $3 \mathrm{hr}$ or until mice did not complete the ratio for delivery of one injection within $1 \mathrm{hr}$. After stable baseline of responding (number of injections not varying by $>20 \%$ over 3 consecutive days), saline was substituted for cocaine to test extinction of lever pressing (i.e., maximum of four injections over 3 consecutive days). Subsequently, access to a condensed milk solution was substituted for saline to test reinstatement of lever pressing for a nondrug reinforcer. Extinction and reinstatement were also tested under the PR schedule, and the experiment endpoint was the stable baseline of responding for condensed milk.

\section{RESULTS \\ Novelty- and cocaine-induced locomotion}

Because novelty-induced locomotion has been associated with activation of the mesolimbic DA system (Hooks and Kalivas, 1995) and with sensitivity to the behavioral and reinforcing effects of psychostimulants (Piazza et al., 1989; Hooks et al., 1991; Marinelli and White, 2000), the locomotor responses of 5-HT2C receptor mutant mice to a novel environment, and subsequently to cocaine, were examined. Analysis of total locomotor behavior during the preinjection periods revealed elevated activity levels in mutant mice, with both mutant and WT animals displaying habituation over the $4 \mathrm{~d}$ period (Fig. 1a). Analysis of the time course of locomotor activity revealed that, during their first exposure to the activity chambers, mutants exhibited hyperactivity associated with reduced within-session habituation (Fig. 1b). On the second day, mutants remained hyperactive relative to WT mice, and their initial locomotor activity levels declined less than WT levels, indicating that between-session habituation was also impaired in these animals (Fig. $1 b, c$ ). With each successive day of exposure, the activity levels of the mutants declined to WT levels more rapidly (Fig. $1 b-e$ ), and by day 3 , no phenotypic differences in the locomotor responses to the saline injections were observed (Fig. $2 a, b)$ (see Materials and Methods). In contrast, mutants displayed markedly enhanced locomotor responses to cocaine, characterized by a dose-dependent increase in peak locomotor activity (Fig. 2b-e). Analysis of the total distance traveled in the hour after cocaine injection also revealed elevated locomotor responses to cocaine in 5-HT2C receptor mutant mice (Fig. 2a). To determine whether these findings reflected phenotypic perturbations of cocaine metabolism, levels of cocaine or cocaine metabolites were measured after intraperitoneal cocaine administration and found to be normal in the mutants (see Materials and Methods).

\section{Cocaine-induced DA release}

To test the hypothesis that 5-HT2C receptors regulate the effects of cocaine on mesolimbic DA transmission, extracellular DA levels in the NAcc were examined after cocaine administration to 5-HT2C receptor mutant and WT mice. To determine whether the 5-HT2C receptor mutation alters mesolimbic and nigrostria- 

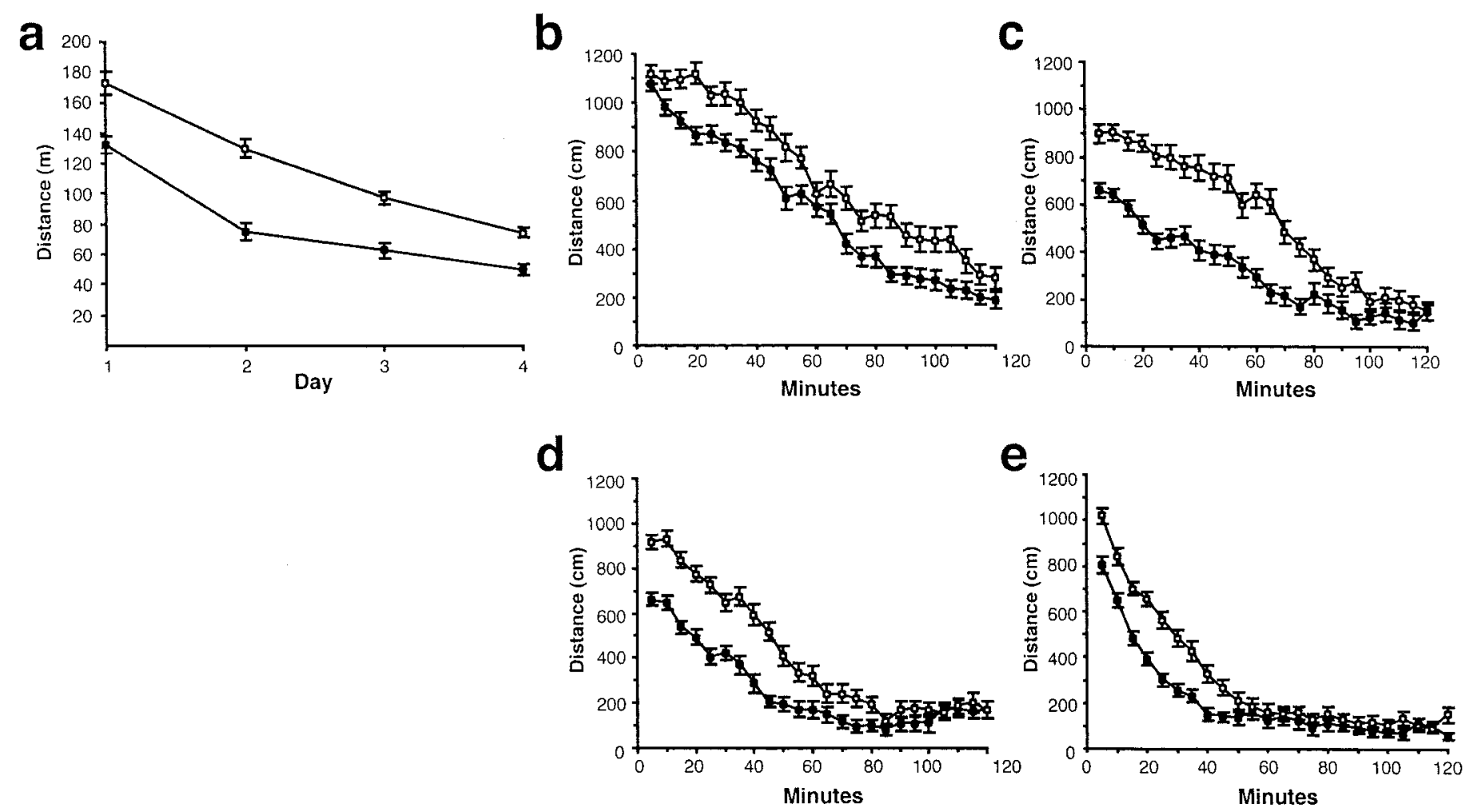

Figure 1. Novelty-induced locomotion and habituation. $a$, Distance traveled during the first $2 \mathrm{hr}$ in the locomotor monitoring apparatus on days $1-4$ for mutant $(n=62)$ and WT $(n=63)$ mice. A $2 \times 4$ ANOVA with day as a repeated measure demonstrated a significant effect of day $\left(F_{(3,121)}=130.2\right.$; $p<0.0001)$ and genotype $\left(F_{(1,123)}=50.9 ; p<0.0001\right)$ and an interaction of day and genotype $\left(F_{(3,121)}=5.9 ; p=0.001\right)$ for distance traveled in the $2 \mathrm{hr}$ before injection. Also shown is distance traveled during $5 \mathrm{~min}$ bins for the first $2 \mathrm{hr}$ of exposure to the activity monitoring apparatus for days $1-4$ (b-e, respectively). In all figures, values represent mean \pm SEM, with WT indicated by filled symbols and mutant indicated by open symbols.

tal dopaminergic responses to cocaine in a similar manner, extracellular DA levels were also examined in the DStr. In vivo microdialysis revealed no significant phenotypic differences in baseline dialysate DA concentration in either the NAcc or DStr. Similarly, no phenotypic differences were observed in the cocaine-induced increase in DStr DA levels. However, the cocaine-induced increase in NAcc DA levels was significantly greater in the mutants (Fig. 3). Consistent with these findings, some (but not all) previous studies revealed 5-HT2C receptor antagonists to preferentially increase DA levels in the NAcc (Di Giovanni et al., 2000; Gobert et al., 2000). The current results indicate that cocaineinduced activation of 5-HT2C receptors selectively dampens its stimulatory effect on mesoaccumbens but not on nigrostriatal DA transmission. Together, the present data support the hypothesis that serotonergic inhibition of mesolimbic DA transmission, resulting from 5-HT2C receptor activation, modulates both reactivity to novelty and the psychostimulant effects of cocaine.

\section{Cocaine self-administration}

To examine the impact of the 5-HT2C receptor mutation on the reinforcing properties of cocaine, an operant self-administration procedure was performed. Thirteen mutant and $15 \mathrm{WT}$ mice were initially trained to lever press for a condensed milk solution and subsequently for cocaine. Mice of both genotypes reliably self-administered cocaine within approximately four sessions, under a schedule where one cocaine injection $\left(1 \mathrm{mg} \cdot \mathrm{kg}^{-1}\right.$. injection $^{-1}$ ) was delivered on each active lever press. After stable baseline responding was obtained in 10 mutant and $13 \mathrm{WT}$ mice, animals were switched to a PR schedule, where the number of active lever presses required to deliver one injection of cocaine progressively increased within the session, and failure to obtain the injection within $1 \mathrm{hr}$ ended the session. The total number of injections received reflected the motivation of the animals to self-administer cocaine, thus reflecting its reinforcing efficacy (Rocha et al., 1998a). Five mutants and two WT mice did not complete self-administration experiments because of loss of catheter patency and consequent extinction of lever pressing but were tested for reinstatement. Stable baseline under PR was obtained in eight mutant and $11 \mathrm{WT}$ mice. 5-HT2C receptor null mutant mice pressed the active lever approximately twice as many times as the WT mice and consequently obtained a significantly larger number of cocaine injections. This difference was only observed for cocaine; both mutant and WT mice extinguished leverpressing behavior at a comparable rate when saline was substituted for cocaine and reinstated lever pressing to the same extent when condensed milk was reintroduced as the reinforcer (Fig. 4). Therefore, it is unlikely that persistence of lever-pressing behavior per se was responsible for the observed increase in cocaine self-administration among mutants. Together, these results confirm that the reinforcing efficacy of cocaine is increased in the absence of 5-HT2C receptors.

\section{DISCUSSION}

Here we report that mice lacking the 5-HT2C receptor exhibit increased responsiveness to novelty and increased sensitivity to the psychostimulant and reinforcing effects of cocaine. Moreover, the increased sensitivity of these animals to the behavioral effects 

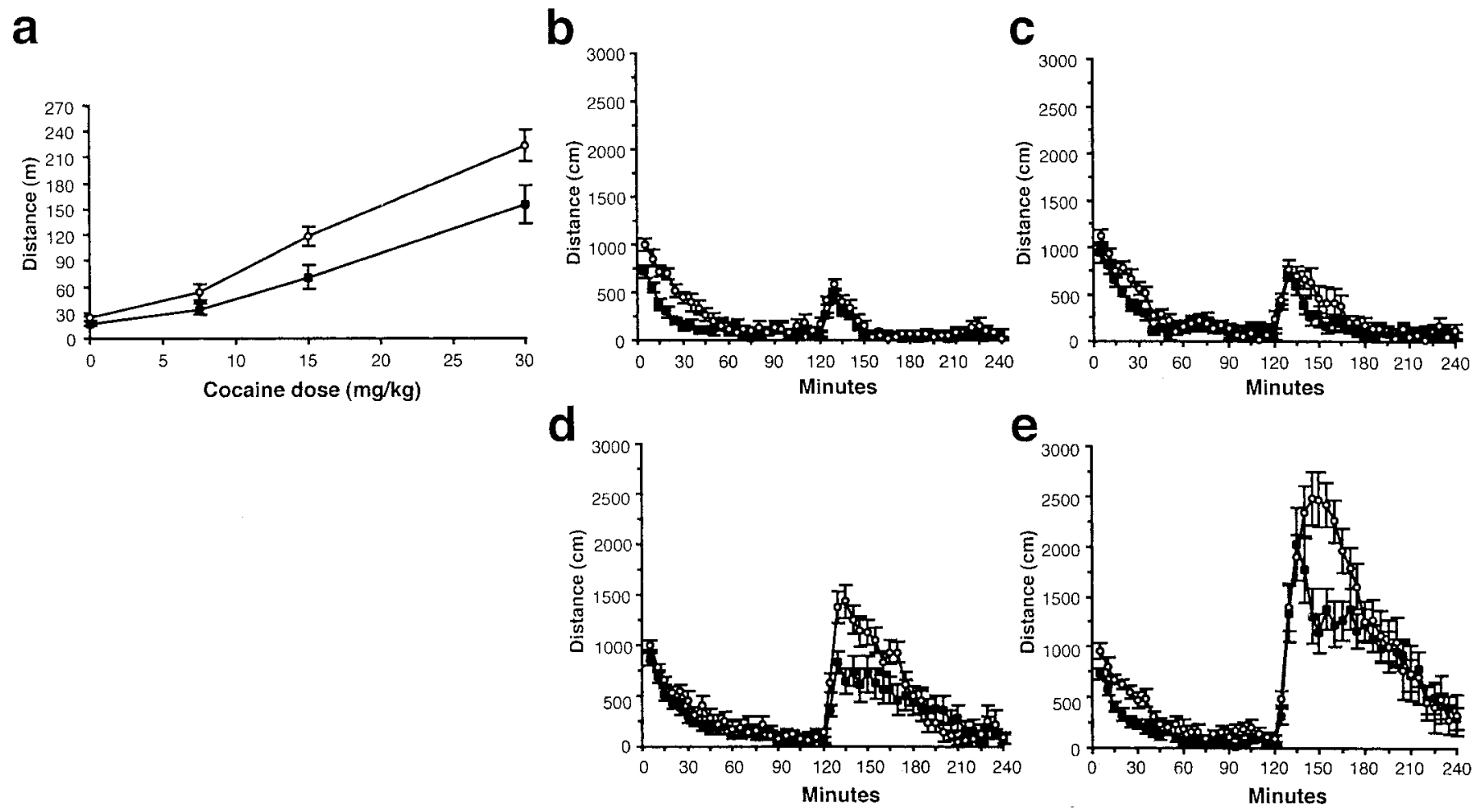

Figure 2. Effect of cocaine administration on locomotion. $a$, Distance traveled during the first hour after cocaine injection. A $2 \times 4$ ANOVA for dose and genotype revealed a significant effect of dose $\left(F_{(3,117)}=67.3 ; p<0.0001\right)$ and genotype $\left(F_{(1,117)}=14.9 ; p<0.001\right)$ but no interaction. Also shown is distance traveled during 5 min bins on day 4 with $0(b), 7.5(c), 15(d)$, and $30(e) \mathrm{mg} / \mathrm{kg}$ cocaine given by intraperitoneal injections at 120 min. The peak locomotion values for the 5-HT2C receptor mutants were significantly different from those of the WT mice $\left(F_{(1,117)}=8.2 ; p=0.005\right)$ and increased significantly with dose $\left(F_{(3,117)}=85.7 ; p<0.0001\right)$ without an interaction of dose and genotype.

of cocaine is accompanied by enhanced cocaine-induced increases in NAcc DA levels. This is in accord with previous evidence associating mesolimbic DA transmission with psychostimulant-induced locomotor activity (Hooks and Kalivas, 1995) and with the predisposition to self-administer cocaine (Robledo and Koob, 1993). Together, these results indicate that 5-HT systems may modulate novelty responses as well as the locomotor stimulant and reinforcing properties of cocaine through the suppression of mesolimbic DA transmission in a process involving 5-HT2C receptors.

Several lines of evidence implicate activation of mesolimbic DA pathways in novelty preference and novelty exploration, whereas activation of brain 5-HT systems produces opposing behavioral effects. For example, lesions disrupting mesolimbic DA pathways reduce exploration of novel environments (Hooks and Kalivas, 1995). Moreover, rodent lines exhibiting enhanced mesolimbic DA transmission, such as DA transporter (DAT) null mutant (Gainetdinov et al., 1999), DAT hypomorphic mutant mice (Zhuang et al., 2001), and rats with increased susceptibility to psychostimulant self-administration (Piazza et al., 1989; Cools et al., 1990), display increased locomotor responses to environmental novelty. Conversely, activation of serotonergic neurotransmission has been proposed to promote risk assessment/harm avoidance behaviors, suppressing responses to novelty (Cloninger, 1987). Thus, suppression of serotonergic activity produced by intraventricular injection of 5,7-dihydroxytrytamine (Lyness and Moore, 1981) and by electrolytic raphe nucleus lesions enhances locomotor responses to novelty (Geyer et al., 1976a,b; Dray et al., 1978). In contrast, mice with enhanced serotonergic activity resulting from mutations of the
5-HT transporter and inhibitory 5-HT1A autoreceptor display diminished exploration of novel and aversive environments (Bengel et al., 1998; Heisler et al., 1998; Parks et al., 1998; Ramboz et al., 1998; Parsons et al., 2001).

It is possible that 5-HT2C receptor-mediated inhibition of mesolimbic DA function may contribute to the effects of 5-HT on novelty-related behavior. Accordingly, firing rates of VTA DA neurons are suppressed by administration of 5-HT2C receptor agonists; conversely, firing rates are enhanced by 5-HT2C receptor antagonist treatment (Di Giovanni et al., 1999; Di Matteo et al., 2000). Previous anatomical and electrophysiological studies indicated that these effects may result from the activation of inhibitory GABAergic interneurons expressing 5-HT2C receptors (Eberle-Wang et al., 1997; Gobert et al., 2000; Di Giovanni et al., 2001). The observed absence of phenotypic differences in baseline NAcc dialysate DA levels using standard in vivo microdialysis methods does not preclude potential alterations in dopaminergic neurotransmission, because spillover of neurotransmitters into the extracellular space may not parallel synaptic release (Parsons and Justice, 1994). Additional studies using the no net flux quantitative microdialysis method will provide a more sensitive indication of basal mesolimbic DA neurotransmission.

Although these findings lead to the prediction that 5-HT2C receptor antagonists would enhance the locomotor and reinforcing properties of cocaine, pharmacological manipulation of 5-HT2C receptors has produced inconsistent results (Lacosta and Roberts, 1993; Peltier et al., 1994; Callahan and Cunningham, 1995; McCreary and Cunningham, 1999; McMahon et al., 2001). For example, administration of the $5-\mathrm{HT} 2 \mathrm{C} / 2 \mathrm{~B}$ receptor antago- 
a

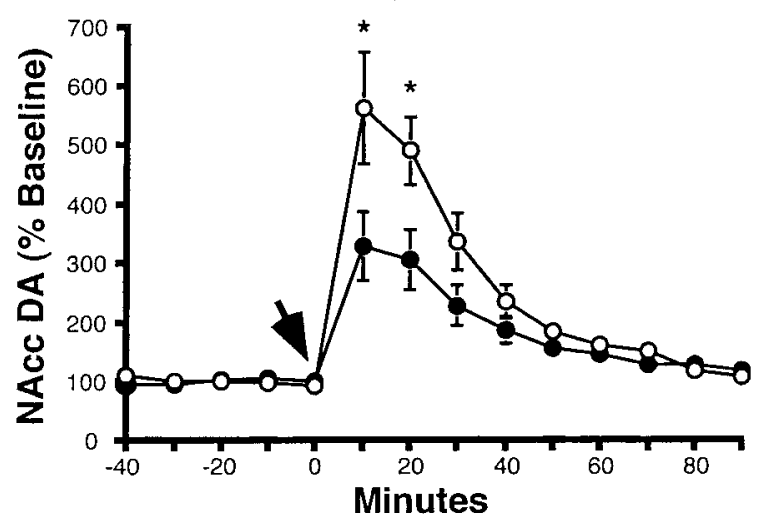

b

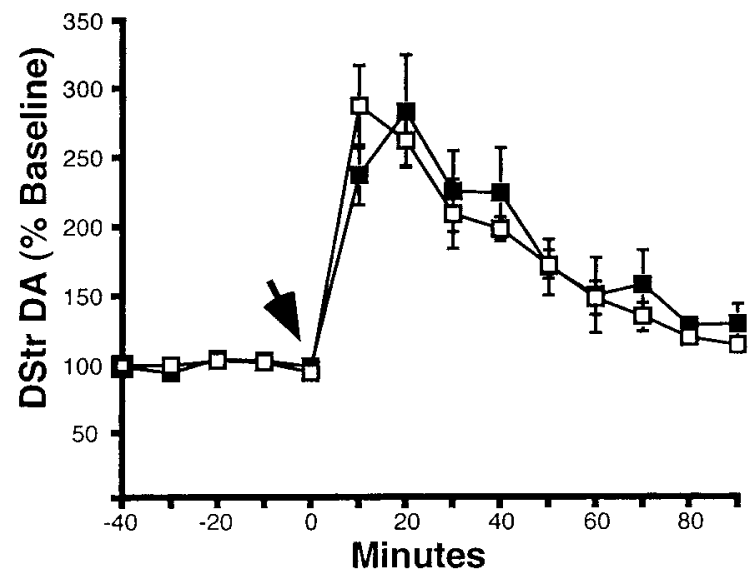

Figure 3. Effect of cocaine administration on DA levels. DA dialysate concentrations were analyzed by mixed factorial repeated-measures ANOVA. Significant differences among individual means were confirmed by Fisher's post hoc tests. Baseline dialysate DA levels from the NAcc and the contralateral DStr of WT $(n=10$; NAcc, $2.9 \pm 0.5 \mathrm{nM}$; DStr, $4.2 \pm 0.4$ $\mathrm{nM})$ and mutant ( $n=9$; NAcc, $3.8 \pm 1.3 \mathrm{nM}$; DStr, $5.6 \pm 0.8 \mathrm{nM})$ mice were not significantly different. The effect of cocaine $(15 \mathrm{mg} / \mathrm{kg}$; arrow $)$ on dialysate DA levels from each region is thus expressed as the percentage change from baseline. $a$, Cocaine induced a significant increase in NAcc DA levels $\left(F_{(9,53)}=35.8 ; p<0.0001\right)$ with a significant effect of genotype $\left(F_{(1,7)}=4.7 ; p<0.05\right)$ as well as a significant genotype-by-time interaction $\left(F_{(9,153)}=3.6 ; p<0.0005\right)$. Subsequent simple effects analyses revealed that NAcc DA levels were significantly higher in 5-HT2C mutant mice relative to $\mathrm{WT}$ controls at both the 10 and 20 min postcocaine time points ( $p<0.05$ at each time point) as denoted by asterisks. $b$, Cocaine also significantly elevated DStr DA levels over time $\left(F_{(9,153)}=35.8 ; p<\right.$ $0.0001)$ but with no significant effect of genotype.

nist 5-methyl-1-(3-pyridylcarbamoyl)-1,2,3,5-tetrahydropyrrolo [2,3-f]indole to rats was found to attenuate cocaine-induced hyperactivity at low doses but to enhance the hyperactivity at high doses (McCreary and Cunningham, 1999). In another study, the 5-HT2C receptor agonist $(S)$-2-(6-chloro-5-fluoroindol-1-yl)-1methylethylamine) fumarate (Ro 60-0175) reduced cocaineinduced hyperactivity, an effect that was blocked by pretreatment with the 5-HT2C receptor antagonist 6-chloro-5-methyl-1-[(2-[(2methyl-3-pyridyl)oxy]-5-pyridyl)carbamoyl]-indoline (SB 242084) (Grottick et al., 2000). In contrast, enhancement of cocaineinduced locomotor activity was not seen after microinjections of the moderately selective 5-HT2C receptor antagonist 8-[5-(2,4- a

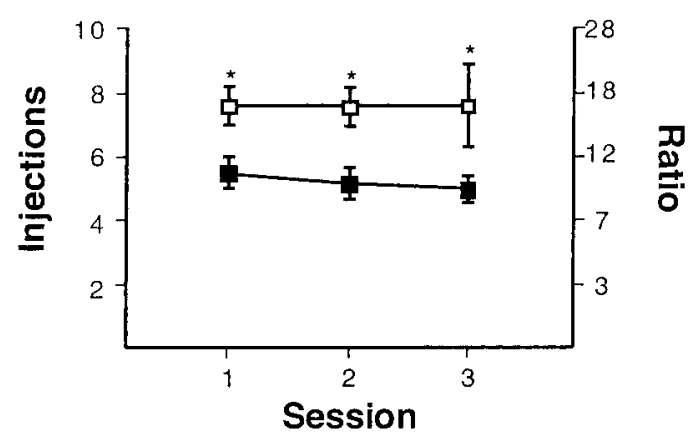

b
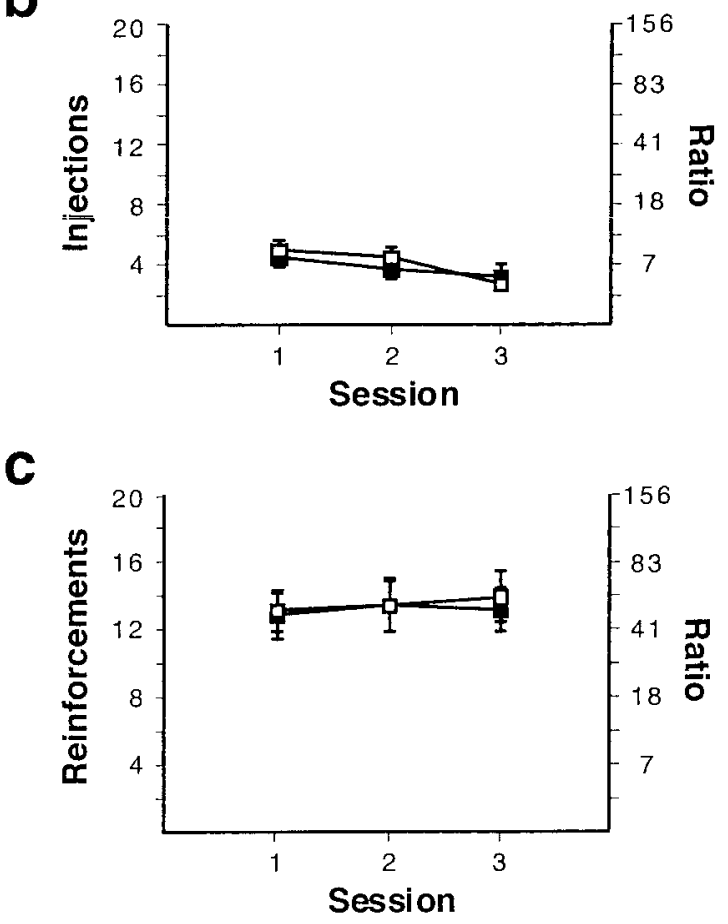

Figure 4. Cocaine self-administration, extinction, and food reinstatement. Values indicate reinforcers obtained by mutant and WT mice under a PR schedule during three consecutive sessions of stable responding ( $x$-axis). Left $y$-axes refer to the total number of reinforcers obtained, and right $y$-axes refer to the corresponding number of active lever presses (ratio completed) for delivery of each reinforcer. $a$, Cocaine self-administration: Mutants completed a ratio of $\sim 20$ lever presses, compared with 10 by WT mice, and thus obtained significantly more cocaine injections. Repeated-measures ANOVA confirmed a significant effect of genotype for the number of cocaine injections $\left(F_{(1,19)}=7.5 ; p<0.05\right)$ but no effect of session or session-by-genotype interaction. Asterisks indicate significant $(p<0.05)$ phenotypic differences. $b$, Extinction: When saline was substituted for cocaine, mutant and WT mice extinguished lever pressing at a comparable rate. Repeated-measures ANOVA confirmed a significant effect of session on the number of saline injections within subjects $\left(F_{(3,51)}=21.6 ; p<0.0001\right)$ but no effect of genotype or session-bygenotype interaction. $c$, Reinstatement with nondrug reinforcer. After saline substitution, condensed milk was made available, and both groups reinstated lever-pressing behavior at a comparable rate. Repeatedmeasures ANOVA confirmed a significant effect of session within subjects on the number of milk reinforcers obtained $\left(F_{(3,72)}=25.3 ; p<0.0005\right)$ but no effect of genotype or session-by-genotype interaction.

dimethoxy-5-(4-trifluoromethylphenylsulfon-amido)phenyl-5oxopentyl)]-1,3,8-triazaspiro[4.5]decane-2,4-dione hydrochloride (RS 102221) into the rat VTA, and injections into the NAcc attenuated cocaine-induced locomotor activity (McMahon et al., 
2001). The contribution of 5-HT2C receptors to the reinforcing and discriminative stimulus properties of cocaine is also unclear. Although the 5-HT2A/B/C receptor antagonist ritanserin failed to block these properties of cocaine (Peltier et al., 1994), administration of agonist Ro 60-0175 reduced operant responses for cocaine, an effect blocked by pretreatment with the 5-HT2C receptor antagonist SB 242084 (Grottick et al., 2000). In contrast, intra-NAcc administration of the 5-HT2C receptor antagonist RS 102221 reduced the stimulus effects of cocaine (Filip and Cunningham, 2002).

The enhanced locomotor effects of cocaine in 5-HT2C receptor mutants are in accord with the hypothesis that cocaine-related responses mediated by mesolimbic DA systems are disinhibited in these mice. Additional support was provided by the observation that cocaine-induced elevations of extracellular DA levels in the NAcc were enhanced in mutant mice. Interestingly, a similar enhancement was not seen in the DStr, consistent with electrophysiological studies indicating that 5-HT2C receptor agonists have a more pronounced influence on mesolimbic than on nigrostriatal DA pathways (Di Giovanni et al., 2000). In light of established associations between psychostimulant self-administration, novelty-induced locomotor activity, and mesolimbic DA function, we predicted that the absence of 5-HT2C receptors would lead to enhanced cocaine self-administration. The enhanced reinforcing effects of cocaine in 5-HT2C receptor mutant mice were confirmed by the elevated breakpoints exhibited by the mutants in a progressive ratio procedure. Together, these findings indicate that 5-HT2C receptors mediate inhibitory serotonergic influences on the locomotor stimulant and reinforcing properties of cocaine through the suppression of mesolimbic DA transmission.

Although the 5-HT2C receptor plays a prominent role in mediating the serotonergic suppression of behavioral responses to cocaine, these 5-HT2C receptor-mediated effects are unlikely to fully account for the complex influences of 5-HT on psychostimulant responses. Recent evidence indicates that cocaine-induced elevations of 5-HT levels may actually contribute to cocaine responses under some circumstances. Thus, cocaine-mediated blockade of 5-HT reuptake has been implicated in the preserved reinforcing effects of this drug in mice lacking the DAT (Rocha et al., 1998b; Sora et al., 2001) and in the ability of cocaine to induce striatal c-fos expression (Bhat and Baraban, 1993). These findings are consistent with evidence that activation of other 5-HT receptors, such as the 5-HT1B and 5-HT3 receptor subtypes, opposes the inhibitory influence of 5-HT on psychostimulant responses (Kankaanpää et al., 1996; Parsons et al., 1998). For example, the pharmacological stimulation of 5-HT1B receptors potentiates cocaine-induced increases in mesolimbic DA neurotransmission and enhances the locomotor and reinforcing effects of cocaine (Johnson et al., 1992; Cameron and Williams, 1994; Parsons et al., 1998). Thus, unopposed activation of 5-HT1B receptors may contribute to the enhanced cocaine responses observed in 5-HT2C receptor mutant mice. Analogous opposing influences of 5-HT2C and 5-HT1B receptors on locomotor responses to the nonselective 5-HT receptor agonist $m$-chlorophenylpiperazine have been observed in previous studies of 5-HT2C receptor mutant and WT mice (Heisler and Tecott, 2000). Finally, in addition to regulating the activity of VTA DA neurons, 5-HT systems may also influence responses to novelty and cocaine through mechanisms involving 5-HT2C and additional 5-HT receptor subtypes expressed in other brain regions.

Associations between neural mechanisms regulating responses to novelty and substance abuse liability have also been observed in humans, as indicated by elevated novelty-seeking trait scores in human populations susceptible to drug abuse (Wills et al., 1994; Cloninger et al., 1995). The clinical relevance of the present findings is further indicated by an observed association between a common allelic variant of the gene encoding the 5-HT2C receptor and the human personality trait of reward dependence (Kühn et al., 1999). In this context, the present findings support the possibility that the 5-HT2C receptor subtype may contribute to serotonergic influences on novelty seeking, reward pathways, and susceptibility to cocaine dependence in humans. In light of the lack of effective pharmacological treatments for cocaine abuse (Kranzler et al., 1999), novel treatment strategies that exploit the influence of serotonergic transmission on cocaine responses warrant consideration. However, recent studies have revealed 5-HT selective reuptake inhibitors (SSRIs) to be generally ineffective for the treatment of cocaine dependence (Kranzler et al., 1999). These disappointing responses to SSRIs may be attributable to the lack of specificity in the manner in which they alter serotonergic neurotransmission. Global increases in synaptic 5-HT resulting from reuptake blockade could lead to nonspecific activation of multiple 5-HT receptor subtypes with opposing influences on cocaine responses. The present results reveal a prominent role for 5-HT2C receptors in the serotonergic suppression of cocaine responses, indicating that selective 5-HT2C receptor agonist treatments may represent a promising novel approach for treating cocaine abuse and dependence.

\section{REFERENCES}

Azmitia EC, Segal M (1978) An autoradiographic analysis of the differential ascending projections of the dorsal and median raphe nuclei in the rat. J Comp Neurol 179:641-668.

Bengel D, Murphy DL, Andrews AM, Wichems CH, Feltner D, Heils A, Mossner R, Westphal H, Lesch KP (1998) Altered brain serotonin homeostasis and locomotor insensitivity to 3,4-methylenedioxymethamphetamine ("ecstasy") in serotonin transporter-deficient mice. Mol Pharmacol 53:649-655.

Benuck M, Lajtha A, Reith MEA (1987) Pharmacokinetics of systemically administered cocaine and locomotor stimulation in mice. J Pharmacol Exp Ther 243:144-149.

Bhat RV, Baraban JM (1993) Activation of transcription factor genes in striatum by cocaine: role of both serotonin and dopamine systems. J Pharmacol Exp Ther 267:496-505.

Brodie MS, Bunney EB (1996) Serotonin potentiates dopamine inhibition of ventral tegmental area neurons in vitro. J Neurophysiol 76:2077-2082.

Callahan PM, Cunningham KA (1995) Modulation of the discriminative stimulus properties of cocaine by $5-\mathrm{HT}_{1 \mathrm{~B}}$ and $5-\mathrm{HT}_{2 \mathrm{C}}$ receptors. J Pharmacol Exp Ther 274:1414-1424.

Cameron DL, Williams JT (1994) Cocaine inhibits GABA release in the VTA through endogenous 5-HT. J Neurosci 14:6763-6767.

Carroll ME, Lac ST, Asencio M, Kragh R (1990) Intravenous cocaine self-administration is reduced by dietary I-tryptophan. Psychopharmacology 100:293-300.

Cloninger CR (1987) A systematic method for clinical description and classification of personality variants. A proposal. Arch Gen Psychiatry 44:573-588.

Cloninger CR, Sigvardsson S, Przybeck TR, Svrakic DM (1995) Personality antecedents of alcoholism in a national area probability sample. Eur Arch Psychiatry Clin Neurosci 245:239-244.

Cools AR, Brachten R, Heeren D, Willemen A, Ellenbroek B (1990) Search after neurobiological profile of individual-specific features of Wistar rats. Brain Res Bull 24:49-69.

Di Giovanni G, De Deurwaerdére P, Di Mascio M, Di Matteo V, Esposito E, Spampinato U (1999) Selective blockade of serotonin-2C/2B receptors enhances mesolimbic and mesostriatal dopaminergic function: a combined in vivo electrophysiological and microdialysis study. Neuroscience 91:587-597.

Di Giovanni G, Di Matteo V, Di Mascio M, Esposito E (2000) Preferential modulation of mesolimbic vs. nigrostriatal dopaminergic function by serotonin( $2 \mathrm{C} / 2 \mathrm{~B})$ receptor agonists: a combined in vivo electrophysiological and microdialysis study. Synapse 35:53-61.

Di Giovanni G, Di Matteo V, La Grutta V, Esposito E (2001) $m$-Chlorophenylpiperazine excites non-dopaminergic neurons in the rat substantia nigra and ventral tegmental area by activating serotonin-2C receptors. Neuroscience 103:111-116. 
Di Matteo V, Di Giovanni G, Di Mascio M, Esposito E (2000) Biochemical and electrophysiological evidence that RO 60-0175 inhibits mesolimbic dopaminergic function through serotonin(2C) receptors. Brain Res 865:85-90.

Dray A, Davies J, Oakley NR, Tongroach P, Vellucci S (1978) The dorsal and medial raphe projections to the substantia nigra in the rat: electrophysiological, biochemical and behavioural observations. Brain Res 151:431-442.

Eberle-Wang K, Mikeladze Z, Uryu K, Chesselet M-F (1997) Pattern of expression of the serotonin $2 \mathrm{C}$ receptor messenger RNA in the basal ganglia of adult rats. J Comp Neurol 384:233-247.

Epstein JF (2000) Substance dependence, abuse and treatment: findings from the 2000 National Household Survey on Drug Abuse. Rockville, MD: United States Department of Health and Human Services, Substance Abuse and Mental Health Services Administration Office of Applied Statistics.

Filip M, Cunningham KA (2002) Serotonin 5-HT(2C) receptors in the nucleus accumbens regulate expression of the hyperlocomotor and discriminative stimulus effects of cocaine. Pharmacol Biochem Behav 71:745-756.

Gainetdinov RR, Wetsel WC, Jones SR, Levin ED, Jaber M, Caron MG (1999) Role of serotonin in the paradoxical calming effect of psychostimulants on hyperactivity. Science 283:397-401.

Geyer MA, Puerto A, Dawsey WJ, Knapp S, Bullard WP, Mandell AJ (1976a) Histologic and enzymatic studies of the mesolimbic and mesostriatal serotonergic pathways. Brain Res 106:241-256.

Geyer MA, Puerto A, Menkes DB, Segal DS, Mandell AJ (1976b) Behavioral studies following lesions of the mesolimbic and mesostriatal serotonergic pathways. Brain Res 106:257-270.

Gobert A, Rivet JM, Lejeune F, Newman-Tancredi A, AdhumeauAuclair A, Nicolas JP, Cistarelli L, Melon C, Millan MJ (2000) Serotonin(2C) receptors tonically suppress the activity of mesocortical dopaminergic and adrenergic, but not serotonergic, pathways: a combined dialysis and electrophysiological analysis in the rat. Synapse 36:205-221

Grottick AJ, Fletcher PJ, Higgins GA (2000) Studies to investigate the role of 5-HT2C receptors on cocaine- and food-maintained behavior. J Pharmacol Exp Ther 295:1183-1191.

Heisler LK, Tecott LH (2000) A paradoxical locomotor response in serotonin 5-HT2C receptor mutant mice. J Neurosci 20:RC71:1-5.

Heisler LK, Chu HM, Brennan T, Danao J, Bajwa P, Parsons L, Tecott LH (1998) Elevated anxiety and antidepressant-like responses in serotonin 5-HT1A receptor mutant mice. Proc Natl Acad Sci USA 95:15049-15054

Herges S, Taylor DA (1999) Modulatory effect of $p$-chlorophenylalanine microinjected into the dorsal and median raphe nuclei on cocaineinduced behaviour in the rat. Eur J Pharmacol 374:329-340.

Herve D, Simon H, Blanc G, Lisoprawski A, Le Moal M, Glowinski J, Tassin JP (1979) Increased utilization of dopamine in the nucleus accumbens but not in the cerebral cortex after dorsal raphe lesion in the rat. Neurosci Lett 15:127-133.

Herve D, Pickel VM, Tong HJ, Beaudet A (1987) Serotonin axon terminals in the ventral tegmental area of the rat: fine structure and synaptic input to dopaminergic neurons. Brain Res 435:71-83.

Hooks MS, Kalivas PW (1995) The role of mesoaccumbens-pallidal circuitry in novelty-induced behavioral activation. Neuroscience 64:587-597.

Hooks MS, Jones GH, Smith AD, Neill DB, Justice Jr JB (1991) Response to novelty predicts the locomotor and nucleus accumbens dopamine response to cocaine. Synapse 9:121-128

Johnson SW, Mercuri NB, North RA (1992) 5-Hydroxytryptamine1B receptors block the $\mathrm{GABA}_{\mathrm{B}}$ synaptic potential in rat dopamine neurons. J Neurosci 12:2000-2006.

Kankaanpää A, Lillsunde P, Ruotsalainen M, Ahtee L, Seppâlä T (1996) 5-HT3 receptor antagonist MDL 72222 dose-dependently attenuates cocaine- and amphetamine-induced elevations of extracellular dopamine in the nucleus accumbens and the dorsal striatum. Pharmacol Toxicol 78:317-321.

Kelland MD, Freeman AS, Rubin J, Chiodo LA (1993) Ascending afferent regulation of rat midbrain dopamine neurons. Brain Res Bull 31:539-546.

Koe BK (1976) Molecular geometry of inhibitors of the uptake of catecholamines and serotonin in synaptosomal preparations of rat brain. J Pharmacol Exp Ther 199:649-661.

Kranzler HR, Amin H, Modesto-Lowe V, Oncken C (1999) Pharmacologic treatments for drug and alcohol dependence. Psychiatr Clin North Am 22:401-423.

Kühn KU, Meyer K, Nöthen MM, Gänsicke M, Papassotiropoulos A, Maier W (1999) Allelic variants of dopamine receptor D4 (DRD4) and serotonin receptor 5HT2c (HTR2c) and temperament factors: replication tests. Am J Med Genet 88:168-172.

Lacosta S, Roberts DC (1993) MDL 72222, ketanserin, and methysergide pretreatments fail to alter breaking points on a progressive ratio schedule reinforced by intravenous cocaine. Pharmacol Biochem Behav 44:161-165.

Loh EA, Roberts DCS (1990) Break-points on a progressive ration schedule reinforced by intravenous cocaine increase following depletion of forebrain serotonin. Psychopharmacology 101:262-266.

Lyness WH, Moore KE (1981) Destruction of 5-hydroxytryptaminergic neurons and the dynamics of dopamine in nucleus accumbens septi and other forebrain regions of the rat. Neuropharmacology 20:327-334.

Marinelli M, White FJ (2000) Enhanced vulnerability to cocaine selfadministration is associated with elevated impulse activity of midbrain dopamine neurons. J Neurosci 20:8876-8885.

McCreary AC, Cunningham KA (1999) Effects of the 5-HT2C/2B antagonist SB 206553 on hyperactivity induced by cocaine. Neuropsychopharmacology 20:556-564.

McMahon LR, Filip M, Cunningham KA (2001) Differential regulation of the mesoaccumbens circuit by serotonin 5-hydroxytryptamine (5HT) 2A and 5-HT2C receptors. J Neurosci 21:7781-7787.

Morrow BA, Roth RH (1996) Serotonergic lesions alter cocaine-induced locomotor behavior and stress-activation of the mesocorticolimbic dopamine system. Synapse 23:174-181.

Parks CL, Robinson PS, Sibille E, Shenk T, Toth M (1998) Increased anxiety of mice lacking the serotonin1A receptor. Proc Natl Acad Sci USA 95:10734-10739.

Parsons LH, Justice Jr JB (1994) Quantitative approaches to in vivo brain microdialysis. Crit Rev Neurobiol 8:189-220.

Parsons LH, Koob GF, Weiss F (1995) Serotonin dysfunction in the nucleus accumbens of rats during withdrawal after unlimited access to intravenous cocaine. J Pharmacol Exp Ther 274:1182-1191.

Parsons LH, Weiss F, Koob GF (1998) Serotonin1B receptor stimulation enhances cocaine reinforcement. J Neurosci 18:10078-10089.

Parsons LH, Kerr TM, Tecott LH (2001) 5-HT1A receptor mutant mice exhibit enhanced tonic, stress-induced and fluoxetine-induced serotonergic neurotransmission. J Neurochem 77:607-617.

Peltier RL, Emmett-Oglesby MW, Thomas WH, Schenk S (1994) Failure of ritanserin to block the discriminative or reinforcing stimulus effects of cocaine. Pharmacol Biochem Behav 48:473-478.

Piazza PV, Demineire JM, Le Moal M, Simon H (1989) Factors that predict individual vulnerability to amphetamine self-administration. Science 245:1511-1513.

Prisco S, Esposito E (1995) Differential effects of acute and chronic fluoxetine administration on the spontaneous activity of dopaminergic neurones in the ventral tegmental area. Br J Pharmacol 116:1923-1931.

Ramboz S, Oosting R, Amara DA, Kung HF, Blier P, Mendelsohn M, Mann JJ, Brunner D, Hen R (1998) Serotonin receptor 1A knockout: an animal model of anxiety-related disorder. Proc Natl Acad Sci USA 95:14476-14481.

Reith ME, Li MY, Yan QS (1997) Extracellular dopamine, norepinephrine, and serotonin in the ventral tegmental area and nucleus accumbens of freely moving rats during intracerebral dialysis following systemic administration of cocaine and other uptake blockers. Psychopharmacology 134:309-317.

Robledo P, Koob GF (1993) Two discrete nucleus accumbens projection areas differentially mediate cocaine self-administration in the rat. Behav Brain Res 55:159-166.

Rocha BA, Scearce-Levie K, Lucas JJ, Hiroi N, Castanon N, Crabbe JC, Nestler EJ, Hen R (1998a) Increased vulnerability to cocaine in mice lacking the serotonin-1B receptor. Nature 393:175-178.

Rocha BA, Fumagalli F, Gainetdinov RR, Jones SR, Ator R, Giros B, Miller GW, Caron MG (1998b) Cocaine self-administration in dopamine-transporter knockout mice. Nat Neurosci [Erratum (1998) 1:330] 1:132-137.

Sora I, Hall FS, Andrews AA, Itokawa M, Li X-F, Wei H-B, Wichems C, Lesch K-P, Murphy DL, Uhl GR (2001) Molecular mechanisms of cocaine reward: combined dopamine and serotonin transporter knockouts eliminate cocaine place preference. Proc Natl Acad Sci USA 98:5300-5305.

Strang J, Johns A, Caan W (1993) Cocaine in the UK-1991. Br J Psychiatry 162:1-13.

Tecott LH, Sun LM, Akana SF, Strack AM, Lowenstein DH, Dallman MF, Julius D (1995) Eating disorder and epilepsy in mice lacking 5HT2C serotonin receptors. Nature 374:542-546.

Van Bockstaele EJ, Cestari DM, Pickel VM (1994) Synaptic structure and connectivity of serotonin terminals in the ventral tegmental area: potential sites for modulation of mesolimbic dopamine neurons. Brain Res 647:307-322.

Van Bockstaele EJ, Chan J, Pickel VM (1996) Pre- and postsynaptic sites for serotonin modulation of GABA-containing neurons in the shell region of the rat nucleus accumbens. J Comp Neurol 371:116-128.

Wills TA, Vaccaro D, McNamara G (1994) Novelty seeking, risk taking, and related constructs as predictors of adolescent substance use: an application of Cloninger's theory. J Subst Abuse 6:1-20.

Wise RA (1984) Neural mechanism of the reinforcing action of cocaine. NIDA Res Monogr 50:15.

Withers NW, Pulvirenti L, Koob GF, Gillin JC (1995) Cocaine abuse and dependence. J Clin Psychopharmacol 15:63-78.

Zhuang X, Oosting RS, Jones SR, Gainetdinov RR, Miller GW, Caron MG, Hen R (2001) Hyperactivity and impaired response habituation in hyperdopaminergic mice. Proc Natl Acad Sci USA 98:1982-1987. 